\section{Making sense of life: explaining biological development with models, metaphors and machines}

\author{
A philosopher looks at developmental biology \\ Evelyn Fox Keller \\ Harvard University Press, Cambridge, MA; 2002. 388 pp. \\ $£ 19.95$, hardback. ISBN 0-674-00746-8
}

Heredity (2004) 92, 270. doi:10.1038/sj.hdy.6800414

\section{Reviewed by M Cobb}

Some people will be irritated by the very existence of this book, which surveys a century of attempts to develop mathematical approaches to developmental biology. The problem will lie not so much in the subject as the author, Evelyn Fox Keller, who many biologists will consider to be doubly damned: she was trained as a theoretical physicist before becoming a philosopher of science. Such prejudices should be put aside: Keller's perspective provides a highly stimulating read, which only the ignorant could dismiss.

For many philosophers of science, physics is 'the' science and the way in which it has developed forms a model that all other sciences are implicitly expected to follow. But biology is not physics, and there will never be a biological equivalent of the physicists' dream of a 'theory of everything', apart from the modern synthesis of natural selection and population genetics. Developmental biology forms a partial exception to this: theoretical and mathematical models have formed a key element to its development, from D'Arcy Thompson, through Lewis Wolpert's 'French Flag' model, right up to the work of Princeton's Institute of Advanced Study.

Keller's aim is to examine the continuities and novelties in the mathematisation of development, and to provide both an historical and philosophical analysis of these features. The book is divided into three equallyweighted parts (models, metaphors and machines), each corresponding to an historical period and to a level of analysis.

The first section focuses on the work of three scientists, two of whom will be familiar - D'Arcy Thompson and Turing, whose work, according to Keller, represented an effective dead end, despite their continued fame. The third, Stéphane Leduc, who worked at the beginning of the last century, is largely forgotten today. Leduc produced a series of striking images showing how inorganic substances could imitate biological phenomena such as chromosomal division - the illustration of 'artificial karyokinesis by diffusion' would deceive many an undergraduate. Although Leduc's work was generally well-received at the time, there were some dissenting voices: a reviewer in Nature was particularly, and rightly, ascerbic.

The second section, which deals with the 'glory days' of molecular biology, shows how the metaphor of a genetic 'programme' helped enrich the growing interest in developmental biology, leading to Lewis Wolpert's conception of 'positional information'. Because Keller roots her account in a thorough understanding of both the biology and the history, giving some telling early quotes from Morgan on the nature of development, this section is particularly effective. Although this is also the least original part of the book - much of the material has been studied many times over by Keller and other historians of the period - her focus on Wolpert and on the later Drosophila work by Nüsslein-Volhard and Wieshaus gives a depth to her analysis that sets it aside from many previous accounts. Final year students or post-graduates should be given this middle section and told not to come back until they have read it thoroughly: it will give some necessary historical depth to their obsession with the latest articles in Cell or Development, and above all it will entertain them and make them think.

The final section will probably be the most contentious, as Keller becomes less of an observer of science and, increasingly, a participant. History may begin yesterday, but many of Keller's comments are about today and tomorrow. There is, of course, no problem with such a breaking down of what are essentially artificial academic boundaries, but Keller can probably expect some rude rebuttal (or more likely, a dismissive silence) from the researchers on artificial life and biological computers whose work she discusses.

Keller opens the final section with a discussion of the return of the image as proof, in particular following the development of spectacularly effective techniques such as GFP expression in living cells. In this chapter on 'The visual culture of molecular embryology', Keller provides a frustratingly brief discussion of the parallels with the late 17th century, when microscopic images took on such power. It is not only the brevity of this chapter that is disappointing: given Keller's training, there is surprisingly little reference to, or use of, the substantial historical and philosophical literature on the meaning of representation in science, and the references to early use of the microscope and the world it revealed are virtually all to secondary sources. There is a fascinating book to be written on this topic, if someone with the appropriate wide-ranging knowledge and interests was to seize the opportunity. Keller's survey can be seen as a tantalizing exploration of some of the issues.

The 'science wars' have soured relations between scientists and philosophers of science, with scientists becoming even more allergic to the views of their colleagues in departments of philosophy and sociology than they were previously. This is unfortunate: as Keller's book shows, an external view of our work can provide not only legitimate comment and study, but can also enrich our own understanding of what we are doing, and why.

$\mathrm{M} \mathrm{Cobb}$

School of Biological Sciences, University of Manchester, UK E-mail: mcobb@man.ac.uk 